\title{
Pemberdayaan Ibu-Ibu PKK dan Kader Posyandu RW 022 Teluk Pucung, Bekasi Utara dalam Penerapan Gema Cermat (Gerakan Masyarakat Cerdas Menggunakan Obat)
}

\author{
Elly Wardani ${ }^{1}$, Rizky Arcinthya Rachmania ${ }^{2}$ \\ 1, 2 Universitas Muhammadiyah Prof. Dr. HAMKA, Indonesia
}

\begin{abstract}
A B S T R A C T
EMPOWERMENT OF PKK WOMEN AND POSYANDU CADRE OF RW 022 TELUK PUCUNG, NORTH BEKASI IN THE APPLICATION OF GEMA CERMAT (INTELLIGENT COMMUNITIES USING MEDICINE). Until now in the midst of society often encountered various problems in the use of drugs, including lack of understanding of the use of appropriate and rational drugs, excessive use of over-the-counter drugs, and a lack of understanding of how to store and dispose of drugs properly. While health workers are still perceived as lacking adequate information about drug use. This is based on the appropriateness of data and information sources collected through visits and good discussions with several representatives of PKK women members and Posyandu Cadres RW 22 Teluk Pucung, North Bekasi. There are still many found, especially North Bekasi residents who sell or exchange used drugs to collectors of used goods in their residential areas or there are still many people who store liquid preparations such as syrup in the refrigerator. The purpose of this activity is to increase understanding of the treatment of drugs in how to get, use, store and dispose of and increase the rational use of drugs through Gema Cermat. The method of activities to solve the problems faced by PKK women and Posyandu cadres is by socializing about the Gema Cermat by filling out the questionnaire before and after the socialization. Based on the results of the pre-test and post-test questionnaires, the participants became more aware of the management of drugs at home and increased knowledge of the use of rational drugs such as antibiotics. The conclusion of this activity is to increase participants' understanding of drug management properly and is expected to be implemented in the family and community environment.
\end{abstract}

\begin{tabular}{llll} 
Keywords: & \multicolumn{4}{c}{ Gema Cermat, PKK Women, Posyandu, Teluk Pucung. } \\
\hline Received: & Revised: & Accepted: & Available online: \\
05.12 .2019 & 08.06 .2020 & 14.08 .2020 & 30.11 .2020 \\
\hline
\end{tabular}

Suggested citation:

Wardani, E., \& Rachmania, R. A. (2020). Pemberdayaan Ibu-Ibu PKK dan Kader Posyandu RW 022 Teluk Pucung, Bekasi Utara dalam penerapan Gema Cermat (Gerakan masyarakat cerdas menggunakan obat). Jurnal Pengabdian Pada Masyarakat, 5(4), 878-888. https://doi.org/10.30653/002.202054.358

Open Access I URL: http://ppm.ejournal.id/index.php/pengabdian/article/view/358

${ }^{2}$ Corresponding Author: Program Studi Farmasi, Fakultas Farmasi dan Sains, Universitas Muhammadiyah Prof. Dr. HAMKA (UHAMKA), Islamic Center, Jl. Delima II/IV Perumnas Klender, Jakarta Timur, 13460, Indonesia. Email: rizky_arcinthya@uhamka.ac.id 


\section{PENDAHULUAN}

Kesehatan adalah keadaan sehat, baik secara fisik, mental, spritual maupun sosial yang memungkinkan setiap orang untuk hidup produktif secara sosial dan ekonomis (Presiden RI, 2009). Pelayanan kesehatan merupakan salah satu unsur penting dalam meningkatkan derajat kesehatan masyarakat yang optimal, bagian yang tidak terpisahkan dari pelayanan kesehatan adalah pelayanan kefarmasian, dimana obat merupakan komponen penting dari pelayanan kefarmasian yang merupakan kebutuhan masyarakat (Kemenkes, 2006).

Sampai saat ini di tengah masyarakat seringkali dijumpai berbagai masalah dalam penggunaan obat. Diantaranya ialah kurangnya pemahaman tentang penggunaan obat tepat dan rasional, penggunaan obat bebas secara berlebihan, serta kurangnya pemahaman tentang cara menyimpan dan membuang obat dengan benar. Sedangkan tenaga kesehatan masih dirasakan kurang memberikan informasi yang memadai tentang penggunaan obat (Anonim, 2015).

Hasil Riset Kesehatan Dasar (Riskesdas) 2013 menunjukkan bahwa 35,2\% rumah tangga menyimpan obat untuk swamedikasi. Dari 35,2\% rumah tangga yang menyimpan obat, $35,7 \%$ di antaranya menyimpan obat keras dan $27,8 \%$ diantaranya $86,1 \%$ antibiotik tersebut diperoleh tanpa resep. Berdasarkan hasil tersebut memicu terjadinya masalah kesehatan baru, khususnya penggunaan antibiotika yang kurang tepat yang digunakan oleh masyarakat karena kurangnya pengetahuan masyarakat tentang obat (Riskesdas, 2013).

Menurut Penelitian Yang Dilakukan Oleh Pratiwi (2016), Tingkat Pengetahuan Mengenai Informasi Obat Menunjukan Tidak Adanya Perbedaan Yang Signifikan Antara Sebelum Dan Sesudah Pemberian Edukasi. Namun Untuk Variabel Sikap, Hasilnya Menunjukkan Signifikan Terdapat Perbedaan Sebelum Dan Sesudah Edukasi Informasi Obat. Begitu Pula Menurut Sambara (2014) Juga Sebanyak 48,52\% Responden Tahu Dan Paham Sedangkan Sebanyak 51,48\% Responden Tidak Tahu Dan Tidak Paham Tentang Cara Penggunaan Obat Yang Benar.

Berdasarkan Hasil Pengabdian Yang Dilakukan Dewi Menunjukkan Bahwa Pemahaman Masyarakat Desa Kumain Terhadap Mendapatkan, Menggunakan, Menyimpan, Dan Membuang Obat Dengan Benar Meningkat (Dewi, 2019). Sikap Masyarakat Dan Tenaga Kesehatan Setempat Akan Pola Penerapan Dari Penyuluhan Yang Telah Diberikan, Seperti Pengetahuan Mengenai Jenis, Penggunaan, Dan Penyimpanan Obat-Obatan Yang Tepat Dan Aman Untuk Digunakan Atau Yang Harus Diwaspadai Pemakaiannya (Budiman, 2014). Meningkatnya Pengetahuan Guru Sekolah Dasar Tentang Macam- Macam Obat, Bentuk Sediaan Obat, Cara Penggunaan Obat, Cara Menyimpan Dan Membuang Obat Yang Sudah Tidak Dipakai Serta Mampu Menerapkan Dan Mendampingi Masyarakat Terutama Tentang Bagaimana Mendapatkan, Menggunakan, Menyimpan Dan Membuang Obat Dengan Baik Dan Benar (Yuliastuti 2018). Edukasi Gema Cermat Dengan Metode Cbia Dapat Meningkatkan Pengetahuan Masyarakat Tentang Swamedikasi. Adanya Peningkatan Pengetahuan Masyarakat Di Btn Mirabuana Kendari Dalam Memilih Obat Bebas Dan Bebas Terbatas Dengan Metode Cbia (Musdalipah 2018). 
Untuk meningkatkan pengetahuan, keterampilan dan kemampuan masyarakat dalam penggunaan obat secara benar, perlu dilakukan upaya bersama antara pemerintah dan masyarakat melalui program pemberdayaan masyarakat secara terpadu dan berkesinambungan melalui Gerakan Masyarakat Cerdas menggunakan Obat (Gema Cermat). Gerakan ini bertujuan untuk meningkatkan pemahaman dan kesadaran masyarakat tentang pentingnya menggunakan obat dengan benar, meningkatkan kemandirian dan perubahan perilaku masyarakat dalam memilih dan menggunakan obat secara benar, dan akhirnya akan meningkatkan penggunaan obat secara rasional, termasuk antibiotik (Kepmenkes, 2015). Dengan memberikan pengetahuan tentang pentingnya penanganan Obat lewat Gema Cermat' diharapkan masyarakat lingkungan Bekasi dapat pemahaman yang tepat tentang obat dan dapat dihindari penggunaan yang salah dan penyalahgunaan obat serta pengobatan akan menjadi lebih tepat di masyarakat.

Target pengabdian adalah warga RW 22 Kelurahan Teluk Pucung Bekasi Utara, baik Ibu-ibu PKK RW 22 maupun kader-kader Posyandu RW 22. Mitra yang dipilih menjadi lokasi pengabdian masyarakat didasarkan pada pertimbangan dan skala prioritas untuk dijadikan sasaran kegiatan. Hal ini berdasarkan kepatutan sumber data dan informasi yang dikumpulkan melalui kunjungan serta diskusi baik dengan beberapa perwakilan anggota ibu-ibu PKK dan Kader Posyandu RW 22 Teluk Pucung, Bekasi Utara. Masih banyak ditemukan khususnya warga Bekasi Utara yang menjual atau menukar obat bekas ke tukang pengumpul barang bekas di wilayah perumahannya ataupun masih banyak masyarakat yang menyimpan obat sediaan cair seperti sediaan sirup di dalam kulkas/lemari pendingin. Profil masyarakat di sebagian warga ini tepat untuk mendapatkan tambahan pengetahuan dan keterampilan yang berguna untuk peningkatan kualitas hidup agar dapat melakukan secara mandiri pengelolaan obat yang baik dan benar. Ibu-ibu PKK RW 22 maupun kader-kader Posyandu RW 22 ini diharapkan sebagai stake holder yang dapat menyebarkan informasi dan dapat menjelaskan leaflet Gema Cermat kepada anggota masyarakat lainnya.

Upaya untuk menyelesaikan permasalahan yang dihadapi yaitu melakukan pre-test secara tertulis terlebih dahulu untuk melihat pemahaman masyarakat terkait penggunanaan obat kemudian melakukan sosialisasi dengan cara menjelaskan dengan persuasive pada mitra masalah yang ada di masyarakat berkaitan dengan pengelolaan obat. Selain sosialisasi dilakukan juga evaluasi pemahaman peserta melalui post test. Tujuan dilaksanakan pengabdian masyarakat Penerapan Gema Cermat (Gerakan Masyarakat Cerdas Menggunakan Obat) pada ibu-ibu PKK dan Kader Posyandu RW 22 Teluk Pucung, Bekasi Utara agar terjadi peningkatan pemahaman perlakuan terhadap obat dalam cara mendapatkan, menggunakan, menyimpan dan membuang serta meningkatkan penggunaan obat yang rasional.

\section{METODE}

Program pengabdian masyarakat ini dilaksanakan pada bulan April - Juni 2019 dengan lokasi kegiatan di POSYANDU Gladiol, RW 22, Kelurahan Teluk Pucung, Bekasi Utara. Peserta kegiatan ini adalah Ibu-Ibu PKK dan Kader Posyandu RW 22 Teluk Pucung, Bekasi Utara. 
Upaya untuk menyelesaikan permasalahan yang dihadapi oleh ibu-ibu PKK dan Kader Posyandu yaitu dengan sosialisasi tentang Gema Cermat (Gerakan Masyarakat Cerdas Menggunakan Obat) yaitu a) tahap persiapan; b) pendampingan; c) penyuluhan; d) sosialisasi dan e) evaluasi.

Persiapan dilakukan 1 bulan menjelang acara dilaksanakan yang meliputi a) pendataan peserta; b) pembuatan poster atau brosur pengelolaan obat; c) tinjauan lapangan tempat pelaksanaan dan d) pemilihan materi yang akan disampaikan. Workshop pengelolaan obat yang tepat seperti cara pemberian sediaan obat cair atau semi solid yang tepat, cara pembuangan obat yang tidak terpakai secara benar.

Pendampingan Ibu-ibu PKK dan Kader Posyandu dengan Tim FFS UHAMKA terkait pengelolaan obat yang tepat dan benar. Pendampingan meliputi penjelasan rinci tentang cara mendapatkan, penggunaan, menyimpan dan membuang obat yang tepat dan benar. Sosialisasi dilakukan dengan cara menjelaskan dengan persuasif pada ibu-ibu PKK dan Kader Posyandu melalui pertemuan-pertemuan ibu-ibu dengan membawa alat peraga praktek seperti obat, alat penyimpan, dan lain-lain. Dalam pelaksanaan kegiatan ini diharapkan para peserta mampu memahami masalah yang ada di masyarakat berkaitan dengan keefektifan pengobatan adalah sosialisasi informasi Gema Cermat sehingga akan terjadi peningkatan pemahaman perlakuan terhadap Obat dalam cara mendapatkan, menggunakan, menyimpan dan membuang. Setelah diberi penyuluhan dan sosialisasi tentang Gema Cermat kepada ibu-ibu PKK dan Kader Posyandu RW 022 Kelurahan Teluk Pucung, dari pihak pemateri akan mengevaluasi melalui post test sehingga dapat diketahui apakah terjadi perubahan peningkatan pemahaman perlakuan terhadap obat dalam cara mendapatkan, menggunakan, menyimpan dan membuang obat serta penggunaan obat yang rasional.

\section{HASIL DAN PEMBAHASAN}

Kegiatan pengabdian ini mengadopsi dari kegiatan yang dilakukan bersama antara pemerintah dan masyaraka dalam melaksanakan peningkatan pengetahuan, keterampilan dan kemampuan masyarakat dalam penggunaan obat secara benar melalui sosialisasi Gema Cermat. Bersamaan dengan sosialisasi tersebut, dilaksanakan pula penunjukan Apoteker Agent of Change (AoC) dengan harapan para Apoteker AoC tersebut memiliki komitmen dan kemampuan mempengaruhi perilaku masyarakat untuk meningkatkan penggunaan obat secara rasional (Anonim, 2019).

Kegiatan ini dilaksanakan pada tanggal 26 Juni 2019 bertempat di Posyandu RW 022 yang dihadiri sebanyak 25 peserta ibu-ibu PKK dan kader Posyandu. Acara ini dimulai dengan koordinasi Ketua RW 022 dan ketua PKK Kelurahan Teluk Pucung, Bekasi Utara untuk menentukan permasalahan yang dihadapi terkait pemahaman tentang obat. Pengetahuan masyarakat untuk pemahaman obat di rumah tangga masih sangat kurang oleh karenanya dipilihkan solusi yaitu dengan sosialisasi Gema Cermat.

Sebelum kegiatan dimulai peserta diwajibkan mengisi kuesioner (pre-test) terlebih dahulu terkait pengetahuan peserta terhadap obat Setelah itu dilakukan sosialisasi kepada peserta tentang Gema Cermat dengan menggunakan media dan alat peraga praktek seperti obat, alat penyimpan, dan lain-lain sehingga mudah dipahami oleh peserta. Hasil persentase pre-test dan post-test responden sebelum dan sesudah 
sosialisasi Gema Cermat terkait pengenalan obat generik berdasarkan gambar 1 sebesar $100 \%$. Hal ini menunjukkan informasi pengetahuan tentang istilah obat generik bagi peserta sudah pernah diketahui sebelumnya sehingga tidak ada perbedaan antara sebelum dan sesudah dilakukan sosialisasi.

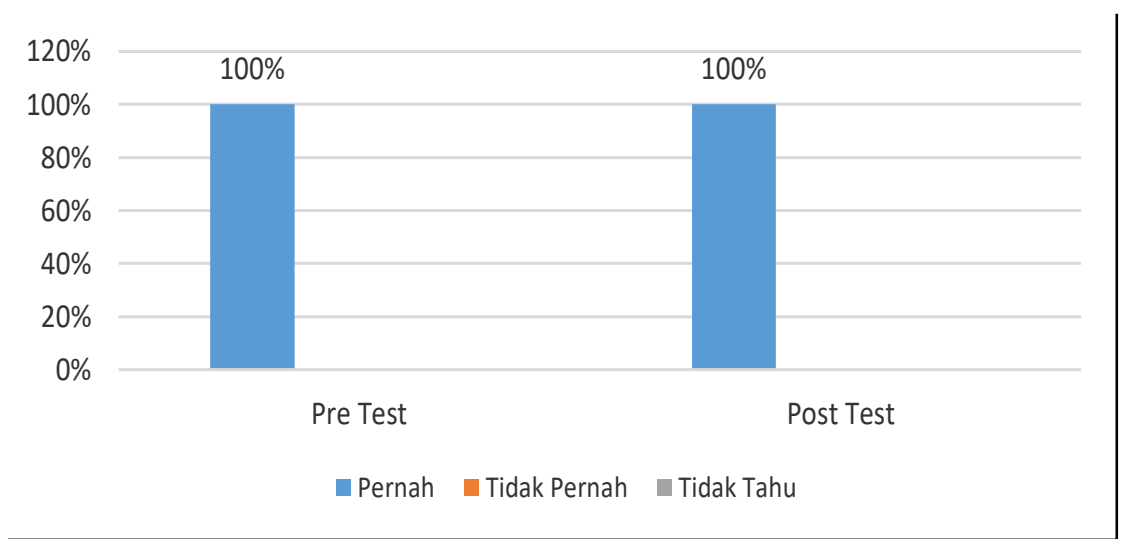

Gambar 1. Diagram Batang Skor Pre Test dan Post Test Pengenalan dengan Obat Generik

Hasil persentase mengenai persepsi obat generik mengalami peningkatan antara hasil pre-test dengan post test (dapat dilihat pada gambar 2). Berdasarkan gambar 2 dapat dilihat peningkatan pengetahuan peserta terhadap persepsi obat generik yaitu obat yang memiliki khasiat sama dengan obat bermerk. Sebelum sosialisasi peserta yang menjawab dengan benar hanya $22,22 \%$ sedangkan setelah sosialisasi meningkat menjadi $66,67 \%$. Obat generik memang dikenal masyarakat sebagai obat yang murah atau obat program dari pemerintah. Secara deskripstif dari hasil persentase pada gambar 2, terdapat $38,89 \%$ peserta yang tingkat pengetahuannya mengetahui obat generik sebagai obat murah atau obat program pemerintah sedangkan $22,22 \%$ peserta yang sudah mengetahui obat generik. Obat generik adalah obat jadi terdaftar yang menggunakan nama generik yaitu nama obat internasional atau nama lazim yang sering dipakai (Anonim, 2006).

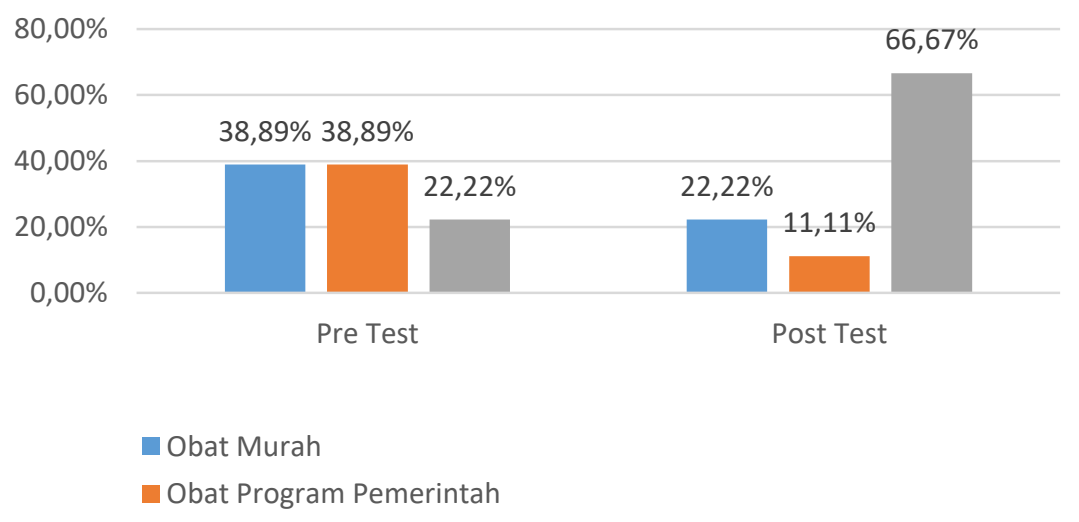

Gambar 2. Diagram Batang Skor Pre Test dan Post Test Persepsi tentang Obat Generik 
Hasil persentase terkait penyimpanan obat yang ada di rumah apakah tersedia atau tidak dapat dilihat pada gambar 3. Berdasarkan gambar 3, dapat diketahui bahwa peserta rata-rata menyimpan obat di rumah.

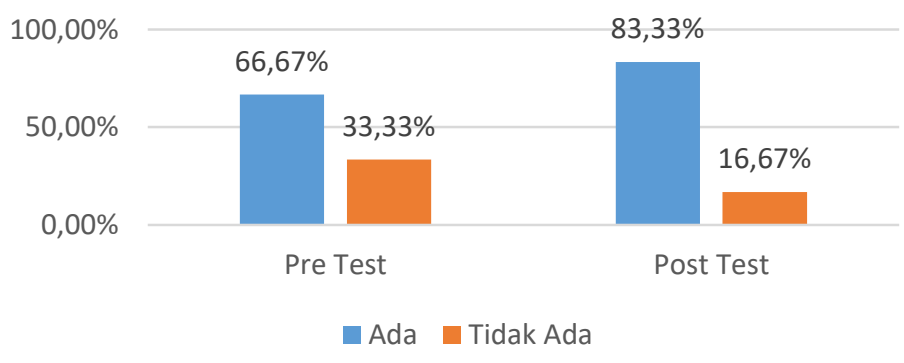

Gambar 3. Diagram Batang Skor Pre Test dan Post Test Penyimpanan Obat oleh Peserta

Berdasarkan hasil persentase pada gambar 4 terkait status obat yang disimpan oleh peserta, sebelum sosialisasi dilakukan sebanyak $50 \%$ peserta menyimpan obat sisa pengobatan, sebanyak $22,22 \%$ digunakan sebagai persediaan obat jika sakit dan sebanyak $27,78 \%$ obat disimpan karena sedang menggunakan obat tersebut. Jika dibandingkan hasil persentase setelah sosialisasi terjadi penurunan persentase untuk status obat yang disimpan dari sisa pengobatan. Hal ini menunjukan adanya perubahan sikap peserta dalam mengelola penyimpanan obat dengan baik dan benar.

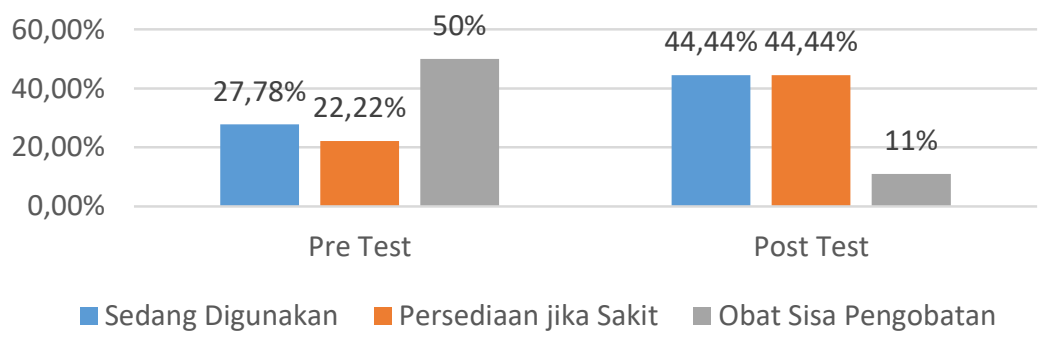

Gambar 4. Diagram Batang Skor Pre Test dan Post Test Status Obat yang disimpan oleh Peserta

Pada gambar 5 dapat dilihat pengetahuan peserta terkait jenis obat yang disimpan oleh peserta. Secara deskriptif sebelum sosialisasi, didapatkan penyimpanan obat peserta sebanyak $61,11 \%$ peserta menyimpan jenis obat bebas, $11,11 \%$ menyimpan jenis obat tradisional. Setelah dilakukan sosialisasi terdapat penurunan persentase penyimpanan jenis obat bebas maupun tradisional. Hal tersebut menunjukan terdapat perbedaan pengetahuan antara sebelum dan setelah sosialisasi. Saat sosialisasi dilakukan peserta dijelaskan klasifikasi golongan obat termasuk perbedaan antara obat bebas, obat bebas terbatas dan obat tradisional. Obat bebas adalah obat yang dijual bebas di pasaran dan dapat dibeli tanpa resep dokter. Obat bebas terbatas adalah obat yang sebenarnya termasuk obat keras tetapi masih dapat dijual atau dibeli bebas tanpa resep dokter, dan disertai dengan tanda peringatan. Dengan demikian pengetahuan peserta akan klasifikasi obat dapat meningkat. 


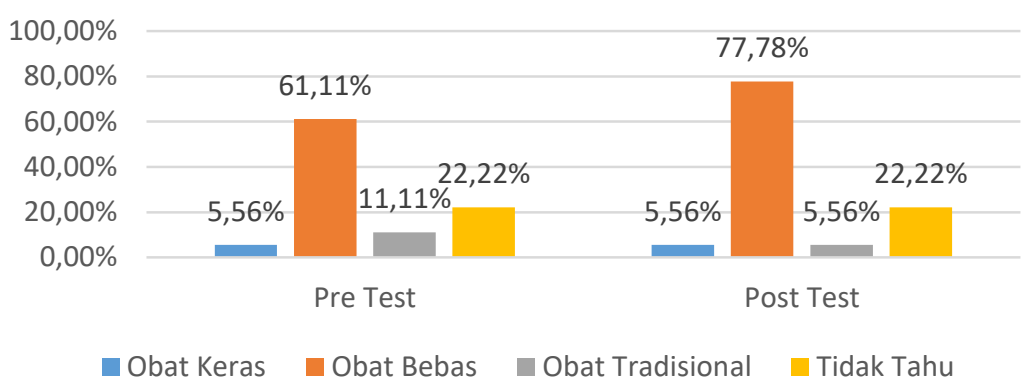

Gambar 5. Diagram Batang Skor Pre Test dan Post Test Jenis Obat yang Disimpan oleh Peserta

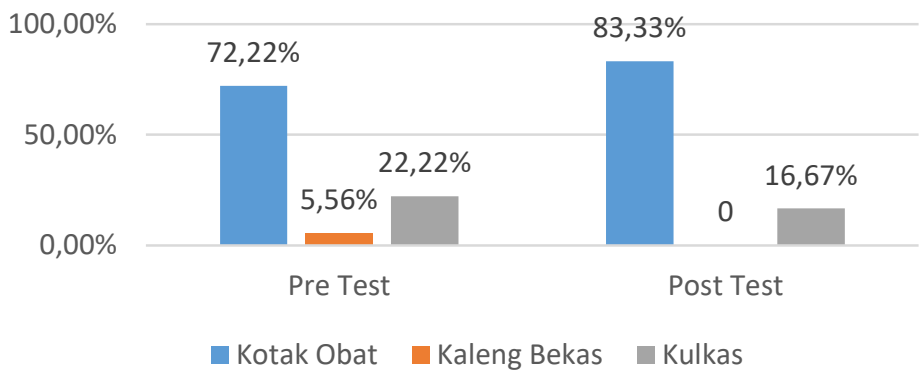

Gambar 6. Diagram Batang Skor Pre Test dan Post Test Tempat Peserta Menyimpan Obat

Sebelum sosialisai banyak peserta yang menyimpan obat belum sesuai dengan penyimpanannya seperti menyimpan di kaleng bekas maupun kulkas (dapat dilihat pada gambar 6). Dengan diberikannya sosialisasi Gema Cermat dapat meningkatkan pengetahuan peserta untuk menyimpan obat sesuai dengan kondisi obat yaitu pada suhu kamar, tidak perlu di dalam kulkas kecuali untuk obat jenis suppositoria. Penyimpanan obat yang baik dapat dilakukan dengan cara menyimpan obat dalam kemasan asli dan dalam wadah tertutup rapat, pada suhu kamar dan terhindar dari sinar matahari langsung atau seperti yang tertera pada kemasan. Simpan obat di tempat yang tidak panas atau tidak lembab karena dapat menimbulkan kerusakan. Jangan menyimpan obat bentuk cair dalam lemari pendingin agar tidak beku, kecuali jika tertulis pada etiket obat. Jangan menyimpan obat yang telah kadaluarsa atau rusak, dan jauhkan dari jangkauan anak-anak (Anonim, 2006).

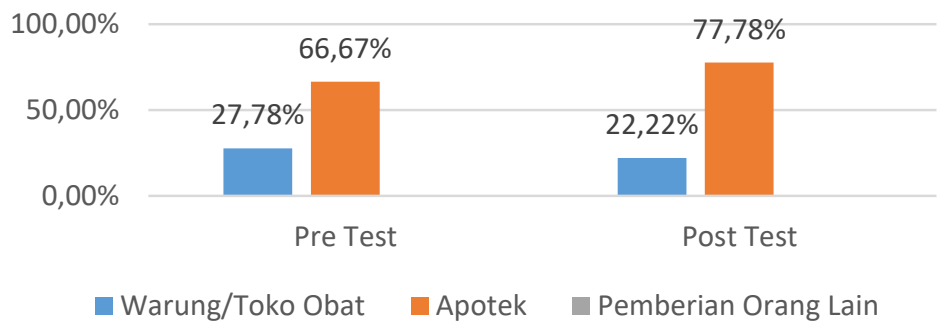

Gambar 7. Diagram Batang Skor Pre Test dan Post Test Cara Peserta Mendapatkan Obat 
Merujuk pada gambar 7 terkait cara peserta mendapatkan obat terdapat kesesuaian antara sebelum dan sesudah sosialisasi dilaksanakan. Persentase peserta mendapatkan obat dari apotek lebih tinggi jika dibandingkan persentase peserta mendapatkan obat dari warung. Dengan sosialiasi Gema Cermat ini diharapkan juga peserta dapat meningkatkan pengetahuannya terhadap tempat pembelian obat yang tepat berdasarkan jenis klasifikasi obatnya.

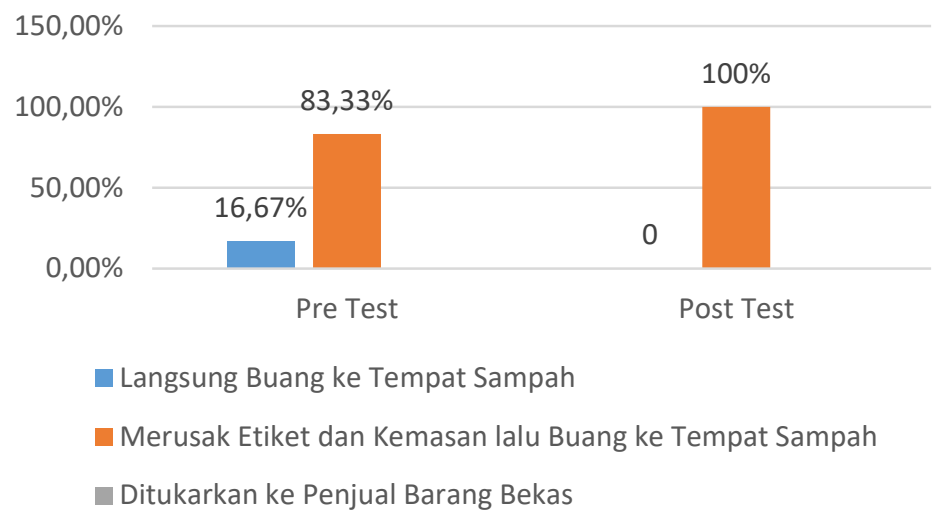

Gambar 8. Diagram Batang Skor Pre Test dan Post Test Cara Peserta Membuang Obat

Pada gambar 8 dapat dilihat pengetahuan peserta bagaimana cara membuang obat dengan benar. Hasil pre-test masih menunjukan sebanyak 16,67\% peserta masih belum benar cara membuang obat secara langsung buang ke tempat sampah. Namun terdapat perbedaan yang signigikan setelah dilakukan sosialisasi semua peserta menjawab dengan benar $(100 \%)$ yaitu dengan cara merusak etiket dan kemasan lalu buang ke tempat sampah.

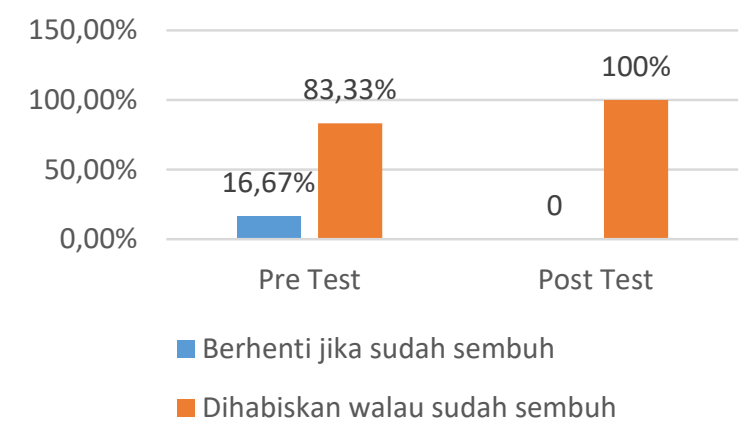

Gambar 9. Diagram Batang Skor Pre Test dan Post Test Penggunaan Antibiotik Oleh Peserta

Kegiatan penyuluhan yang disampaikan selain terkait pengolahan obat di rumah, juga disampaikan bagaimana penggunaan antibiotika dengan benar serta pengetahuan efek samping obat. Berdasarkan gambar 9 menunjukkan hasil persentase sebanyak $16,67 \%$ peserta pada saat menggunakan antibiotik, banyak peserta yang berhenti menggunakan antibiotic jika sudah sembuh. Hal tersebut tidak sesuai dengan 
penggunaan antibiotic yang seharusnya. Setelah dilakukan sosialisasi, semua peserta menjawab dengan benar (100\%) bagaimana penggunaan antibiotik yang seharusnya. Berdasarkan gambar 10, didapatkan hasil yang sesuai antara sebelum dan sesudah sosialisasi terhadap pengetahuan efek samping obat.

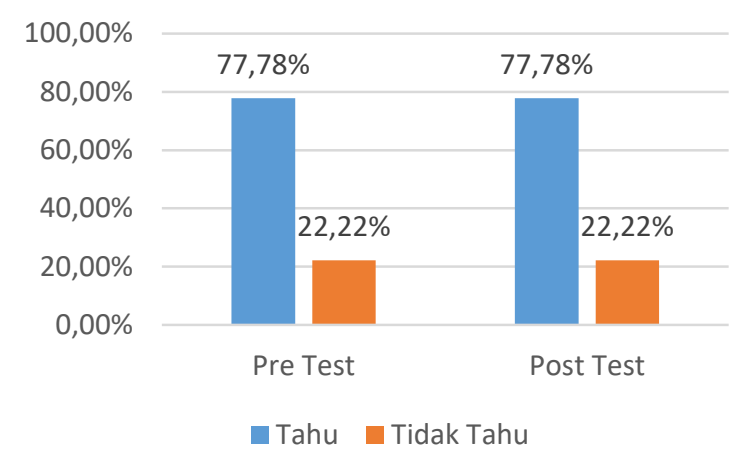

Gambar 10. Diagram Batang Skor Pre Test dan Post Test Pengetahuan Efek Samping Obat

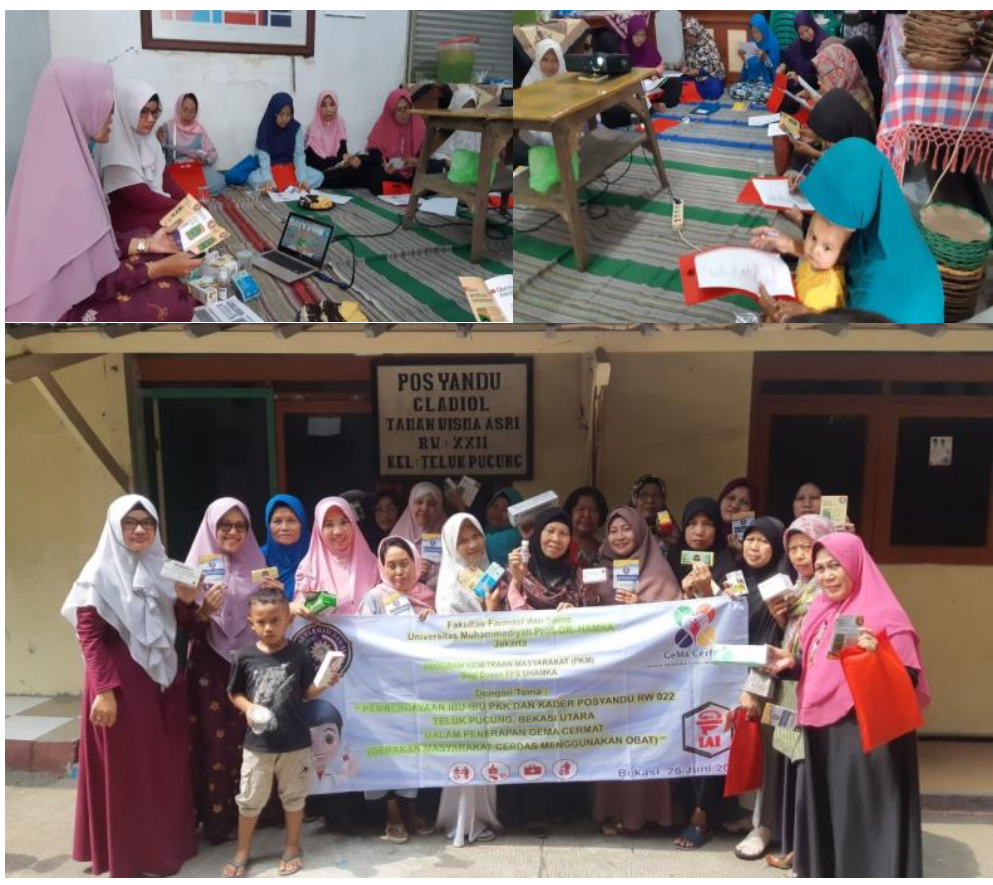

Gambar 11. Foto Rangkaian Kegiatan Gema Cermat

\section{SIMPULAN}

Kegiatan yang diikuti Ibu-ibu PKK dan Kader Posyandu RW 022 Teluk Pucung Bekasi Utara ini berjalan dengan baik dan lancar. Respon peserta terhadap penyuluhan ini cukup tinggi, ditunjukkan dengan angka kehadiran 90\% dari jumlah anggota PKK dan kader Posyandu. Pemahaman masyarakat terhadap pengelolaan obat dengan baik dan benar diharapkan dapat menerapkan dalam lingkungan keluarga dan masyarakat. 


\section{Ucapan Terimakasih}

Penulis mengucapkan terima kasih kepada Lembaga Pengabdian dan Pemberdayaan Masyarakat (LPPM) Universitas Muhammadiyah Prof. Dr. Hamka (UHAMKA) yang telah mendanai program ini dengan nomor kontrak 821/H.04.02/2019 tanggal 22 Mei 2019. Penulis juga mengucapkan terima kasih kepada Fakultas Farmasi dan Sains UHAMKA yang telah mendukung berjalannya program ini. Ucapan terima kasih juga penulis ucapkan kepada Ibu-Ibu PKK dan kader Posyandu RW 22 Teluk Pucung, Bekasi Utara.

\section{REFERENSI}

Dewi A. P., Isna, W., Denia, P., May, V. (2019). Sosialisasi Gerakan Masyarakat Cerdas Menggunakan Obat Di Desa Kumai Kecamatan Tandun Kabupaten Rokan Hulu. Jurnal Pengabdian Masyarakat Multidisiplin, 3(1), 55-61.

Direktorat Bina Farmasi Komunitas dan Klinik, Ditjen Bina Kefarmasian dan Alat Kesehatan (2006), Pedoman Penggunaan Obat Bebas dan Bebas Terbatas. Jakarta: Departemen Kesehatan RI

Harper, L. A., Weaver, K. H., \& Dotson, R. A. (2006). Ammonia emissions from swine waste lagoons in The Utah great basin. Journal of Environmental Quality, 35(1), 224230.

Kemenkes RI (2019). Optimalisasi Peran Apoteker Sebagai Agent of Change (AoC) Gema Cermat. Retrieved November 27, 2019 from http://farmalkes.kemkes.go.id/2019/10/optimalisasi-peran-apoteker-sebagai-agentof-change-aoc-gema-cermat/

Kemenkes. (2015). Kepmenkes No. 427 tahun 2015 tentang Gerakan Masyarakat Cerdas Menggunakan Obat. Jakarta.

Musdalipah, M. (2018). Pemberdayaan masyarakat tentang swamedikasi melalui edukasi gema cermat dengan metode CBIA. Dinamisia: Jurnal Pengabdian Kepada Masyarakat, 2(1), 106-112.

Pratiwi, H., Nuryanti, N., Fera, V. V., Warsinah, W., \& Sholihat, N. K. (2016). Pengaruh edukasi terhadap pengetahuan, sikap, dan kemampuan berkomunikasi atas informasi obat. Kartika: Jurnal Ilmiah Farmasi, 4(1), 10-15.

Presiden Republik Indonesia. Undang-Undang Nomor 36 Tahun 2009 tentang Kesehatan. Jakarta.

Riskesdas. (2013). Riset Kesehatan Dasar 2013. Jakarta: Kementrian Kesehatan Republik Indonesia.

Rokom. (2015). Pemahaman masyarakat akan penggunaan obat masih rendah. Retrieved November 27, 2019 from http://sehatnegeriku.kemkes.go.id/baca/rilismedia/20151127/2813774/pemahamanmasyarakat-akan-penggunaan-obat-masih-rendah/ 
Sambara, J., Yuliani Ni., N., Yantri, B. (2014). Tingkat pengetahuan dan pemahaman masyarakat tentang penggunaan obat yang benar di Kota Kupang tahun 2014. Jurnal Info Kesehatan, 12(1), 699-709.

Yuliastuti, F., Hapsari, W. S., \& Mardiana, T. (2018). Gema Cermat (Gerakan Masyarakat Cerdas Menggunakan Obat) bagi guru sekolah dasar Kecamatan Magelang Selatan Kota Magelang. Community Empowerment, 3(2), 34-37.

\section{Copyright and License}

This is an open access article distributed under the terms of the Creative Commons Attribution 4.0 International License, which permits unrestricted use, distribution, and reproduction in any medium, provided the original work is properly cited.

(C) 2020 Elly Wardani, Rizky Arcinthya Rachmania. 